\title{
Modelagem fenomenológica de biorreator industrial para a produção de etanol
}

\author{
Zanardi, M. S. ${ }^{1}$; Gomes, I. A. ${ }^{2}$; Costa Jr., E. F. ${ }^{1}$ \\ 1 Programa de Pós-Graduação em Engenharia Química, Universidade Federal do Espírito Santo, Alegre, ES, Brasil \\ 2 Linhares Agroindustrial (LASA), Linhares, ES, Brasil
}

\begin{abstract}
Resumo
O etanol ou álcool etílico é um importante bicombustível, sendo uma alternativa eficiente para o petróleo. O Brasil se destaca como o segundo maior produtor de etanol do mundo, sendo pioneiro no uso comercial do álcool combustível. No Brasil, praticamente toda a produção de etanol é proveniente da fermentação pela levedura Saccharomyces Cerevisiae da sacarose, proveniente do caldo da cana-de-açúcar, na ausência de oxigênio. Como cada empresa cultiva suas leveduras, as condições operacionais variam de uma indústria para a outra, devido a diferenças nas cepas de leveduras. Neste contexto, a modelagem dos biorreatores empregados na produção de etanol é importante na simulação de novas condições operacionais, objetivando-se a otimização do processo. Neste trabalho, um biorreator contínuo e perfeitamente agitado é modelado por meio dos balanços dinâmicos de massa para as concentrações de substrato (sacarose), produto (etanol) e de células. A equação empregada para a descrição da cinética da reação e os valores de seus parâmetros foram obtidos da literatura. Resultados da influência das condições operacionais na eficiência do biorreator são apresentados e discutidos, sendo todos coerentes com as informações reportadas na literatura e com a realidade industrial.
\end{abstract}

Keywords (Palavras chaves): etanol, modelagem fenomenológica, fermentação.

\section{Introdução}

O Brasil é o líder mundial na tecnologia de produção de etanol a partir da cana-de-açúcar. A transformação de sacarose em etanol e $\mathrm{CO}_{2}$ (produtos principais) envolve 12 reações em sequência, biocatalisadas pela levedura Saccharomyces Cerevisiae [1]. As etapa principais são a hidrólise da sacarose em glicose e frutose (equação 1) e a produção de etanol em anaerobiose (equação 2).

$$
\begin{aligned}
& \mathrm{C}_{12} \mathrm{H}_{22} \mathrm{O}_{11}+\mathrm{H}_{2} \mathrm{O} \longrightarrow \mathrm{C}_{6} \mathrm{H}_{12} \mathrm{O}_{6}+\mathrm{C}_{6} \mathrm{H}_{12} \mathrm{O}_{6} \\
& \mathrm{C}_{6} \mathrm{H}_{12} \mathrm{O}_{6}\left(\text { (aq) } \stackrel{\text { Levedse }}{\longrightarrow} 2 \mathrm{C}_{2} \mathrm{H}_{5} \mathrm{OH}_{(\text {(aq) }}+2 \mathrm{CO}_{2(\mathrm{~g})}+\mathrm{ATP}\right.
\end{aligned}
$$

A cinética da reação é afetada por diversos fatores, principalmente pela linhagem da levedura. Cada uma das cepas tem suas características próprias, afetadas pelas condições em que o processo fermentativo se desenvolve, tornando as condições operacionais diferentes de uma indústria para a outra [1].

Neste trabalho tem o objetivo de modelar um biorreator contínuo e perfeitamente agitado por meio dos balanços dinâmicos de massa para as concentrações de substrato (sacarose), produto (etanol) e de células. A equação empregada para a descrição da cinética da reação e os valores de seus parâmetros foram obtidos da literatura.

\section{Materiais e métodos}

As seguintes considerações foram adotadas para 0 modelo: (i) mistura ideal, (ii) não há arraste de etanol na saída de $\mathrm{CO}_{2}$, (iii) as vazões volumétricas de entrada e saída são iguais e (iv) volume constante.

Para realizar o balanço material é necessário conhecer a cinética da reação, como cada levedura tem suas características próprias a cinética é muito afetada. Existem várias equações que descrevem a velocidade especifica do crescimento celular $(\mu)$ na literatura. A equação 3 leva em consideração a inibição pelo substrato e o envenenamento pelo produto [2].

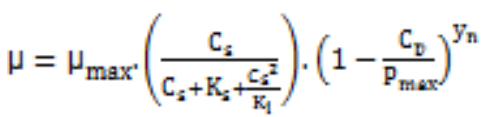

Onde $\mu_{\max }$ representa a velocidade especifica de reação, $\mathrm{C}_{\mathrm{s}}$ é a concentração de saída do substrato, $\mathrm{K}_{\mathrm{s}}$ corresponde a constante de saturação do substrato, $\mathrm{K}_{\mathrm{i}}$ é a constante de inibição pelo substrato, $P_{\max }$ a concentração máxima de produto, $C_{p}$ a concentração final de produto e $y_{n}$ o fator potência de inibição do produto.

As equações de taxa para cada componente se relacionam pela seguinte equação [3]. 
$\mathrm{r}_{\mathrm{x}}=\mathrm{C}_{\mathrm{X}} \mu=\mathrm{r}_{\mathrm{s}^{\mathrm{r}}} \mathrm{Y}_{\mathrm{x} / \mathrm{s}}=\mathrm{r}_{\mathrm{p}}^{\mathrm{r}} \frac{\mathrm{Y}_{\mathrm{x} / \mathrm{s}}}{\mathrm{Y}_{\mathrm{p} / \mathrm{s}}}$

Onde representa $C_{x}$ a concentração de células, $Y_{x / s} 0$ rendimento em células e $Y_{p / s} 0$ rendimento em etanol. De posse dessas informações e do balanço dinâmico de massa o modelo matemático para cada componente substrato (equação 5), etanol (equação 6) e células (equação 7) foi realizado.

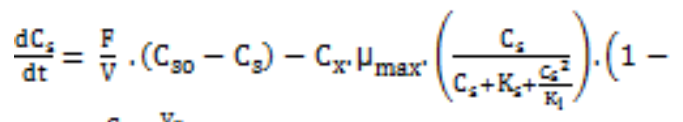

$$
\begin{aligned}
& \left.\frac{C_{\mathrm{D}}}{\mathrm{P}_{\max }}\right)^{\mathrm{Y}_{\mathrm{n}}} \times \frac{1}{\mathrm{P}_{\mathrm{x} j \mathrm{~s}}}
\end{aligned}
$$

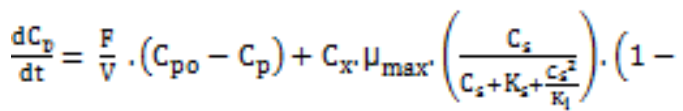

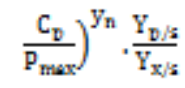

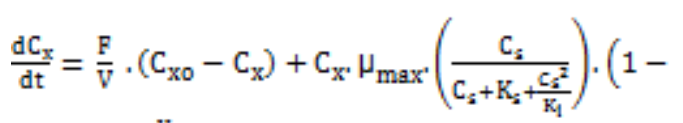

$$
\begin{aligned}
& \left.\frac{C_{D}}{P_{\max }}\right)^{Y_{n}}
\end{aligned}
$$

Onde $\mathrm{V}$ representa o volume do reator e $\mathrm{F}$ a vazão dos componentes. Os parâmetros que melhor satisfaz a equação (3) para situação industrial são $\mathrm{K}_{\mathrm{s}}=3 \mathrm{Kg} / \mathrm{m}^{3}$, $P_{\max }=92 \mathrm{Kg} / \mathrm{m}^{3}, \mathrm{~K}_{\mathrm{i}}=27 \mathrm{Kg} / \mathrm{m}^{3}, \mu_{\max }=0,0001388 \mathrm{~s}^{-1} \mathrm{e}$ $\mathrm{y}_{\mathrm{n}}=5$,3. A razão $\mathrm{Y}_{\mathrm{x} / \mathrm{s}}$ e $\mathrm{Y}_{\mathrm{p} / \mathrm{s}}$ adotadas foram 0, 026 e 0,426 respectivamente [4]. O sistema de EDOs resultante é altamente não linear e não tem solução analítica, sendo integrado numericamente por meio do método de Runge-Kutta de quarta ordem.

\section{Resultados e discussão}

$\mathrm{Na}$ indústria avaliada o volume do primeiro reator, analisado neste trabalho, é $800 \mathrm{~m}^{3}$, a vazão 0,0444 $\mathrm{m}^{3} / \mathrm{s}$ e C Cso é $115 \mathrm{Kg} / \mathrm{m}^{3}$. A Figura 1 ilustra a concentração dos componentes com o tempo. A concentração de substrato diminui enquanto a de produto aumenta, até atingir o estado estacionário. Para atingir a condição industrial a concentração de célula foi estimada, sendo o valor de entrada no reator igual $13 \mathrm{~kg} / \mathrm{m}^{3}$.

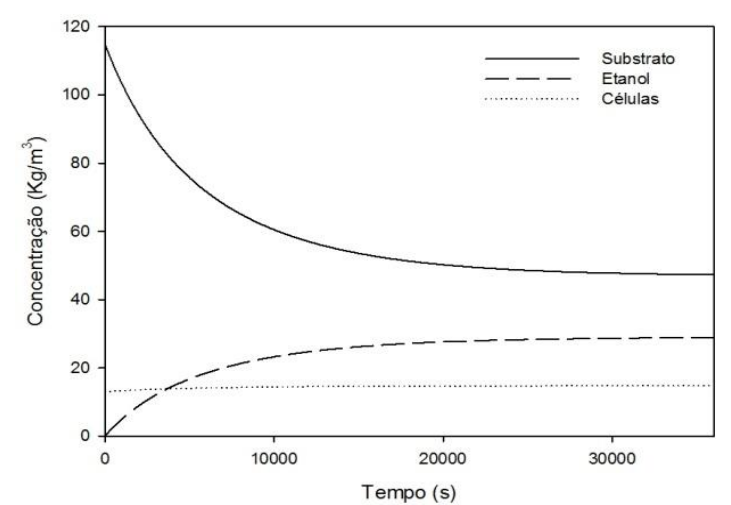

Figura 1: Variação da concentração com o tempo
A concentração de álcool inicial no processo afeta a produção. Para as mesmas condições da Figura 1 diferenciada apenas por Cpo igual a $10 \mathrm{Kg} / \mathrm{m}^{3}$ há uma queda de $31 \%$ de etanol em relação à $\mathrm{Cpo}$ nulo. Isso ocorre freqüentemente em reatores em série.

Outra condição a ser analisada é a vazão de alimentação. Na indústria a vazão é função da quantidade de cana moída, esse valor pode variar afetando a produção. A figura 2 mostra que um aumento nessa vazão acarreta na diminuição da produção. O efeito inverso ocorre no aumento do volume do reator.

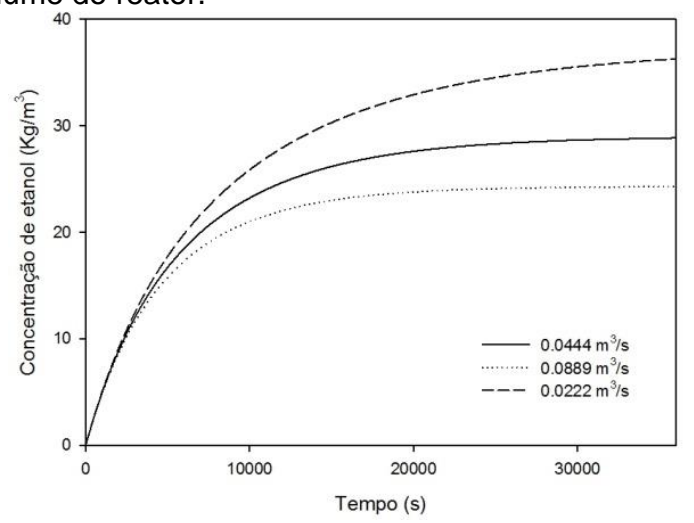

Figura 2: Variação da concentração de etanol com a mudança da vazão de alimentação.

\section{Conclusão}

A modelagem em biorreatores é importante para se conhecer a variação das concentrações com o tempo e os fatores que influenciam na eficiência do processo. Como continuação deste trabalho, para se descrever o processo real em estudo, serão avaliadas diferentes equações cinéticas, sendo os parâmetros das mesmas estimados.

\section{Referências}

[1] LIMA, U. A.; AQUARONE, E.; BORZANE, W.; SCHMIDEL, W. Biotcnologia industrial: Processos Fermentativos e enzimáticos. V3. São Paulo: Edgard Bluncher, 2001.

[2] TOSETTO, G. M. Influência da Matéria-Prima no Comportamento Cinético de Levedura na Produção de Etanol. 95 f. Dissertação (Mestrado em Engenharia Química), Programa de Pós-Graduação em Engenharia Química, Universidade estadual de Campinas, São Paulo, 2002.

[3] LEVENSPIEL, O. Engenharia das reações químicas. São Paulo: Edgard Bluncher, 2000.

[4] PORTO, L. M. Modelagem de processo industrial de fermentação alcoólica contínua com reatores de mistura ligados em série I. 139 f. Dissertação (Doutorado em Engenharia Química), Programa de Pós-Graduação em Engenharia Química, Universidade Estadual de Campinas, São Paulo, 2005. 